\title{
Development of fetal nicotine and muscarinic receptors in utero
}

C. $\mathrm{MaO}^{1}, \mathrm{~J} . \mathrm{Lv}^{1}$,

H. Li ${ }^{3}$, Y. Chen ${ }^{1}$, J. $\mathrm{Wu}^{1}$ and $\mathrm{Z}$. $\mathrm{Xu}^{1,2}$
${ }^{1}$ Soochow University School of Medicine, Suzhou, China

${ }^{2}$ Loma Linda University School of Medicine, Loma Linda, CA, USA

${ }^{3}$ Center for Reproduction, Suzhou Hospital, Suzhou, China

\section{Correspondence \\ Z. Xu \\ Soochow University \\ School of Medicine \\ Suzhou 215123 \\ China \\ E-mail: xuzhice@suda.edu.cn or \\ zxu@llu.edu}

Research supported by NSFC

(No. 30570915), JiangSu High

Education NSF (No. 05KJB310109),

JiangSu NSF Key Project Grant

(No. BK2006703), Soochow University

Research Grant (No. EE134501),

Suzhou Social Development Grant

(No. ssy0632), Suzhou Key Grant

(No. SZS0602), and Soochow

University Program Project Grant

(No. 90134602)

Presented at the International Symposium of Neuroendocrinology

"Neuroendocrine control of body

fluid homeostasis: past, present

and future". Ribeirão Preto, SP,

Brazil, September 1-3, 2006.

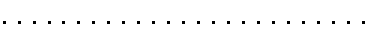

Received October 11, 2006 Accepted February 13, 2007

\begin{abstract}
The role of acetylcholine in the central and peripheral nervous systems is well established in adults. Cholinergic modulation of vascular functions and body fluid balance has been extensively studied. In the embryo-fetus, cholinergic receptors are widespread in the peripheral and central systems, including smooth muscle and the epithelial lining of the cardiovascular, digestive, and urinary systems, as well as in the brain. Fetal nicotine and muscarinic receptors develop in a pattern (e.g., amount and distribution) related to gestational periods. Cholinergic mechanisms have been found to be relatively intact and functional in the control of vascular homeostasis during fetal life in utero at least during the last third of gestation. This review focuses on the development of fetal nicotine and muscarinic receptors, and provides information indicating that central cholinergic systems are well developed in the control of fetal blood pressure and body fluid balance before birth. Therefore, the development of cholinergic systems in utero plays an important role in fetal vascular regulation, gastrointestinal motility, and urinary control.
\end{abstract}

Key words

- Acetylcholine

- Muscarinic/nicotinic

receptors

- Fetus

- Swallowing

- Vascular homeostasis

\section{Introduction}

Cholinergic systems play an important role in body fluid and vascular regulation. Progress has been made in demonstrating that in utero development can have an impact on prenatal and postnatal health, and certain putative mechanisms, including cholinergic mechanisms, have been proposed. The present mini-review focuses on the progress in the development of cholinergic receptors and on how cholinergic mechanisms mediate fetal vascular and body fluid regulation.

\section{Development of peripheral cholinergic receptors in the heart, urinary, and digestive systems}

\section{Fetal cardiovascular systems}

Acetylcholine (ACh) acts as a transmitter in the developing heart of humans. Muscarinic responses to ACh can be detected from the 4th post-conception week onwards after the initiation of the first heartbeats. Under in vitro conditions, muscarinic-cholinergic transmission can be demonstrated in 10- to 12-week-old human hearts and the in utero 
fetal tachycardiac response to atropine can be demonstrated within 15-17 weeks. The parasympathetic-cholinergic control of the developing human heart then becomes functional and plays a role in antenatal cardiac functions (1).

Muscarinic agonists inhibit the pacemaker current of embryonic pig ventricular myocytes and can reverse $\beta$-adrenergic stimulation (2). Muscarinic ACh receptors (mAChR) in the embryonic cardiomyocytes of rats are involved in the inhibition of Ltype calcium current (3). Expression of rat choline acetyltransferase (ChAT) and acetylcholinesterase (AChE) mRNA was observed from 15 embryonic days in the neural tissue covering the dorsocranial wall of the atria. mAChR subtypes $\left(\mathrm{M}_{1}, \mathrm{M}_{2}, \mathrm{M}_{4}\right)$ were observed at the same location as AChE and ChAT mRNA, while $\mathrm{M}_{1}$ and $\mathrm{M}_{4}$ receptors showed a low level of expression in the atrial myocardium during the fetal period. ChAT, AChE, and mAChR $\left(\mathrm{M}_{1}, \mathrm{M}_{2}, \mathrm{M}_{4}\right)$ mRNA are usually co-localized in the rat cardiac ganglia (Table 1). $\mathrm{M}_{1}, \mathrm{M}_{2}, \mathrm{M}_{3}$, and $\mathrm{M}_{4}$ receptors were detected in the cultured neonatal ventricular myocytes of rats $(4,5)$. No $\mathrm{M}_{3}$ or $\mathrm{M}_{5}$ expression was observed in the embryonic heart. Low concentrations of ACh $(\leq 1$ $\mathrm{nM}$ ) increased automaticity in the neonatal rat heart, with the excitatory response being mediated via stimulation of a post-synaptic $\mathrm{M}_{1}$ receptor in non-innervated myocytes. Sympathetic innervation prevents the functional expression of the post-synaptic myocardial $\mathrm{M}_{1}$ receptor. Pharmacological analysis with $\mathrm{mAChR}$ antagonists has indicated that $M_{1}$ and $M_{2}$ receptors are important mediators of the response to carbachol in neonatal atria (6). These data suggest that cholinergic mechanisms start to function in the control of fetal heart and vascular systems during the prenatal period, at least at $70 \%$ of gestation in different species observed. In addition, it seems that the cholinergic mechanism via $M$ receptors is critical to fetal cardiovascular control in utero.
Fetal swallowing, digestive and urinary systems

Fetal swallowing is an important behavior during the period of in utero development. This behavior causes fetal intake of amniotic fluid that may influence fetal body fluids and vascular volume. In the digestive tract, cholinergic systems are already present during prenatal life. The development of cholinergic regulation of upper gastrointestinal motility occurs in near-term fetal rabbits. Atropine injected into the fetal rabbit during the late gestational period could suppress upper gastrointestinal motility, indicating that fetal cholinergic mechanisms may be functional in fetal digestive systems during late gestation (7-9). Many studies conducted on adults have demonstrated that cholinergic stimulation such as administration of carbachol plays an important role in water intake and body fluid regulation. For example, a previous study suggested that this portion of the hypothalamus contains two populations of neural elements which participate in the regulation of food and water intake and are preferentially sensitive to adrenergic and cholinergic stimulation, respectively (10). Although several reports have shown that fetal swallowing (fluid intake) can be controlled by angiotensin and osmotic mechanisms $(11,12)$, there are very few studies regarding the functional development of fetal swallowing produced by cholinergic stimulation or mechanisms in utero. A preliminary study by our group (Mao C, Shi L, Xu Z, Central application of carbachol increased fetal swallowing activity in the ovine fetus, unpublished data) indicated that intracerebroventricular injection of carbachol into chronically prepared near-term sheep can increase fetal swallowing activity. This has opened intriguing possibilities for future studies of the cholinergic system, its antagonists, its receptors, and central pathways in the development of fetal swallowing and body fluid control. 
Despite the very limited data currently available on cholinergically stimulated fetal swallowing, many studies have demonstrated cholinergic development in the digestive tract of the fetus. $\mathrm{M}_{2}$ receptors are predominant in the gastric smooth muscle of rabbit fetuses. Administration of cholinergic agonists or antagonists potentially modulates fetal gastrointestinal motility and absorption of amniotic fluid $(13,14)$. Intravenous bethanechol improves electromechanical coordination in the fetal colon. Cholinergic stimulation evokes local contractile/expulsive mechanisms in meconium passage in sheep fetuses at nearterm. Cholinergic mechanisms may be critical to the regulation of colonic motility since defects in the cholinergic system have been reported in infants born with Hirschsprung's disease, in which a delay in meconium passage was clinically observed (15).

The urinary system is also important for water and salt reabsorption and excretion in the regulation of body fluids. Cholinergic receptors appear very early in the human fetal bladder since contractile responses to bethanechol, competitively blocked by atropine, were observed in the prepared detrusor muscle at three months and in the sphincter at four months. Later, the density of cholinergic receptors increases in the detrusor muscle, whereas there is a progressive reduction in the sphincter (16). The density of mAChR was significantly greater than the density of $\alpha$ - or $B$-adrenergic receptors in the smooth muscle of the fetal bovine bladder during the midgestational period (17). Voluntary or involuntary contraction of the detrusor muscle of the urinary system mainly depends on $\mathrm{mAChR}$ stimulated by ACh that is released from parasympathetic terminals (18). The $\mathrm{M}_{2}$ receptor is the predominant subtype in the bladder and uterus. The bladder of the fetal rabbit has been shown to respond to muscarinic stimulation $(19,20)$. The development of sheep fetuses is associated with increased contractile activation between 65 and 140 gestational days, and atropine-increased bladder capacity is observed at 120 days' gestation (21-23). M receptormediated mechanisms are important in the regulation of fetal urinary systems, including the bladder, at pre-term and near-term.

Table 1 shows the development of peripheral cholinergic elements in the fetal heart and in the urinary and digestive systems during different gestational periods and in different species. In general, cholinergic systems, including their receptors and key enzymes, are developed and functional in the cardiovascular, urinary, and digestive systems regarding body fluid balance. However, functional development of cholinergic mechanisms in the control of fetal swallowing, kidney function, and vascular volume regulation is still unclear. Further studies are needed to clarify the possible contribution of fetal cholinergic mechanisms to the development of systems that control body fluids.

\section{Development of fetal brain cholinergic receptors and their effects on vascular and body fluid control}

ACh receptors are differentially expressed throughout the central nervous system, where

Table 1. Development of peripheral cholinergic elements in the fetal heart and in the fetal urinary and digestive systems during different gestational periods and in different species.

\begin{tabular}{|c|c|c|c|c|}
\hline & Heart & Stomach & Colon & Bladder \\
\hline \multicolumn{5}{|l|}{ Human } \\
\hline ChAT & $10-12$ weeks & & & \\
\hline mAChR & $15-17$ weeks & & & 3 months \\
\hline \multicolumn{5}{|l|}{ Rat } \\
\hline ChAT & 15 days & & & \\
\hline $\mathrm{AChE}$ & 15 days & & & \\
\hline mAChR subtypes & $\begin{array}{c}M_{1}, M_{2}, M_{4} \\
15 \text { days }\end{array}$ & & & \\
\hline \multicolumn{5}{|l|}{ Rabbit } \\
\hline mAChR subtypes & & $\begin{array}{c}\mathrm{M}_{2} \\
\text { near-term }\end{array}$ & & $\begin{array}{c}M_{2}, M_{3} \\
3 \text { weeks }\end{array}$ \\
\hline \multicolumn{5}{|l|}{ Sheep } \\
\hline ChAT & & near-term & & \\
\hline mAChR & & & near-term & 65 days \\
\hline
\end{tabular}

ChAT = choline acetyltransferase: $\mathrm{mAChR}=$ muscarinic acetylcholine receptors; $\mathrm{AChE}=$ acetylcholinesterase. 
they play a role in the modulation of neurotransmitter release, neuronal differentiation, regulation of gene expression, and neuronal pathfinding. The nicotinic AChR (nAChR) are ligand-gated ion channels with different $\alpha(\alpha 2-7)$ and $\beta$ (B2-4) units (Table 2). It has been demonstrated that multiple subtypes of neuronal nAChR can be formed from various combinations of subunits, including the $\alpha 4 \beta 2, \alpha 3 \beta 2, \alpha 4 \beta 4$, and $\alpha 7$ subtypes. Most $\mathrm{nAChR}$ in the brain appear to be heteromeric $\alpha 4 \beta 2$, and homomeric $\alpha 7$ (24-26). nAChR is present in the human fetal brain as early as the first trimester, gradually increasing up to mid-gestation and then declining in the third trimester. $\alpha 3,4,5,7$, and $\beta 2,3,4$, but not $\alpha 2$, 6 receptors are expressed in the human fetal brain. $\alpha 5$ levels are higher in the cortex, while $\alpha 7$ levels are higher in the hindbrain, and $\beta 3$ in the cerebellum. $\beta 4$ is equally distributed in all regions, whereas $\beta 2$ levels are higher in the cortex and cerebellum. nAChR decrease in all regions of the human brain after birth (27-30). $\alpha 2,3,7$ in the cortex and $\alpha 4,7$ in the brainstem are increasingly expressed in humans exposed to nicotine (31, 32).

Five subtypes of $\mathrm{mAChR}$ have been identified: $\mathrm{M}_{1}, \mathrm{M}_{3}$, and $\mathrm{M}_{5}$ receptors that are preferentially coupled to G-protein and stimulate phospholipase $\mathrm{C}$, and $\mathrm{M}_{2}$ and $\mathrm{M}_{4}$ receptors that are coupled to G-protein associated with the inhibition of adenylate cy- clase (33). In general, the ontogeny of $\mathrm{mAChR}$ in the human fetal brain shows two distinct phases during in utero development: first, they appear between 16 and 18 weeks and gradually increase up to 20 weeks. Second, there is a lag period between 20 and 24 weeks, at which time the receptor density does not change perceptibly. mAChR decrease in all regions of the human brain after birth $(34,35)$. mAChR are extensively distributed in the striatum, brainstem, cortex, and midbrain, and their levels are relatively lower in the cerebellum and hippocampus. $\mathrm{M}_{1}$ receptors are concentrated mainly in the forebrain regions while $\mathrm{M}_{2}$ receptors dominate in the thalamus $(36,37)$. During middle and late gestation, $\mathbf{M}_{2}$ receptors are abundant in the cerebellum of human fetuses and $\mathrm{M}_{3}, \mathrm{M}_{4}$ receptors appear to predominate in the brainstem (38) (Table 3). High mAChR densities are noted in certain brainstem nuclei that are important for the development of fetal and neonatal behaviors (39). The development of central $\mathrm{N}$ and $\mathrm{M}$ receptors in the fetal brain provides the basis for central cholinergic actions in utero.

During the early development of the brain, the main processes are proliferation of neuronal stem and progenitor cells, migration of different cells to a pre-designated area and differentiation into neurons and glial cells. Cholinergic neurons innervate almost the entire neuraxis and $\mathrm{mAChR}$ are distributed

Table 2. Brain nicotinic acetylcholine receptor (nAChR) levels of human fetuses at different gestational periods.

\begin{tabular}{llrr}
\hline \multicolumn{1}{c}{ First trimester } & Mid-gestation & Late gestation \\
\hline $\begin{array}{l}\text { Cortex } \\
\text { Medulla oblongata }\end{array}$ & $\alpha 3, \alpha 4, \alpha 5^{\star}, \alpha 7, \beta 2^{*}, \beta 3, \beta 4$ & & \\
Pons & $\alpha 3, \alpha 4, \alpha 5, \alpha 7^{*}, \beta 2, \beta 3, \beta 4$ & $\begin{array}{c}\text { nAChR } \uparrow \\
\text { (tegmental nuclei) }\end{array}$ & $\begin{array}{r}\text { nAChR } \downarrow \\
\text { (tegmental nuclei) }\end{array}$ \\
$\begin{array}{l}\text { Cerebellum } \\
\text { Mesencephalon }\end{array}$ & $\alpha 3, \alpha 4, \alpha 5, \alpha 7, \beta 2^{*}, \beta 3^{*}, \beta 4$ & nAChR & nAChR $\downarrow$ \\
Subcortical forebrain & $\alpha 3, \alpha 4, \alpha 5, \alpha 7, \beta 2, \beta 3, \beta 4$ & (periaqueductal gray) & (periaqueductal gray) \\
\hline *The amount of receptors is high. & &
\end{tabular}


throughout the central nervous system (4048). At early stages of embryogenesis, fetal neurons are releasing ACh that triggers the depolarization of adjacent cells in the spinal cord $(49,50)$. Previous studies have shown that $\alpha 7$ receptors play a role in axonogenesis, synaptogenesis, and synaptic plasticity, are also related to developmental neurotoxicants, and increase glutamate release onto postsynaptic NMDA receptors $(51,52)$.

The major populations of cholinergic neurons in the brain include two "projections" located in the pontine reticular formation and in the basal forebrain. These two complexes comprise, in part, the anatomical substrates for the "ascending reticular activating system". The pontine cholinergic system relays its rostral information mainly through thalamic intralaminar nuclei, but it also connects to the basal forebrain and provides a minor innervation of the cortex. The basal forebrain cholinergic complex projects directly to the cortex and the hippocampus, and has a minor connection with the thalamus. The basal forebrain cholinergic complex acts in tandem or in parallel with the pontine cholinergic projection to activate the electro-encephalogram, to increase cerebral blood flow, to regulate sleep-wake cycling, and to modulate cognitive functions (53-55). Abnormal development of the cholinergic basal forebrain has been implicated in numerous developmental disorders such as Rett syndrome and Down syndrome.

Muscarinic cholinergic neurotransmission is involved in fetal breathing. Nearterm ovine fetal swallowing activity occurs predominantly during low-voltage electrocortical activation. Atropine suppressed fetal swallowing activity in the ovine fetus (56), while carbachol increased high-voltage fetal sheep electrocortical activity and breathe amplitude. These effects were mediated by $\mathrm{M}_{1}$ receptors (57). Central cholinergic systems are important in the control of fetal cardiovascular activity. Stimulation of central $\mathrm{mAChR}$ results in hypertension and a change of heart rate in the fetal lamb (58).

Our recent study demonstrated that intracerebroventricular carbachol can increase systolic, diastolic, and mean arterial pressure accompanied by a bradycardia in sheep fetuses (59).

Neuronal activity labeled with c-fos was significantly enhanced after central administration of carbachol in the fetal anterior third ventricle region of the forebrain, and in the area postrema, lateral parabrachial nucleus, nucleus tractus solitarii, and rostral ventrolateral medulla in the hindbrain. This central neural activation labeled with c-fos was associated with cardiovascular changes in sheep fetuses (59). Central cholinergic systems are also involved in fetal hormone secretion that may also contribute to vascular regulation. For example, acetylcholine evoked CRH secretion in Lewis rat fetal hypothalamic cells (60). Notably, hormonal mechanisms may be well developed in the fetal brain for the control of fetal vascular functions.

In summary, both peripheral and central cholinergic systems, particularly cholinergic receptors, are relatively mature before birth in all systems that are linked to the regulation of body fluids. Both $\mathrm{N}$ receptors and $\mathrm{M}$ receptors as well as their subtypes appeared in the fetal cardiovascular, ingestive, and urinary systems as well as in the fetal brain. Cholinergic mechanisms are relatively intact and functional in the control of cardiovascular homeostasis during fetal life in utero in the last third of gestation. It is apparent

Table 3. Brain muscarinic acetylcholine receptors of human fetuses at different gestational periods.

\begin{tabular}{lcccc}
\hline & Forebrain & Thalamus & Cerebellum & Pons \\
\hline $\begin{array}{l}\text { Mid-gestation } \\
\text { Late gestation }\end{array}$ & $M_{1}$ high & $M_{2}$ high & & $M_{3}$ high \\
& & & $M_{2}$ high & $M_{3}$ high \\
\hline
\end{tabular}

Brain muscarinic acetylcholine receptors (mAChR) appear in most regions of the fetal brain between 16 and 18 weeks. $M_{1}, M_{2}$, and $M_{3}$ are mAChR subtypes. "high" indicates that $\mathrm{mAChR}$ is dominant in the region at certain gestational periods. 
that central cholinergic systems are well developed in the control of fetal blood pressure before birth. Although further studies are required to determine the functional development of cholinergic control of fetal body fluid balance and its influence on prenatal and postnatal health, the data obtained so far have opened up intriguing possibilities for future studies of the functional development of drinking behavior regulated by cholinergic mechanisms.

\section{References}

1. Papp JG. Autonomic responses and neurohumoral control in the human early antenatal heart. Basic Res Cardiol 1988; 83: 2-9.

2. Shigenobu K, Tanaka $H$, Satoh $H$. Developmental changes in the pacemaker current and membrane currents of the guinea pig myocardium. Nippon Yakurigaku Zasshi 1996; 107: 259-272.

3. Liang HM, Tang M, Liu CJ, Luo HY, Song YL, Hu XW, et al. Muscarinic cholinergic regulation of L-type calcium channel in heart of embryonic mice at different developmental stages. Acta Pharmacol Sin 2004; 25: 1450-1457.

4. Franco D, Moorman AF, Lamers WH. Expression of the cholinergic signal-transduction pathway components during embryonic rat heart development. Anat Rec 1997; 248: 110-120.

5. Sun LS, Huber F, Robinson RB, Bilezikian JP, Steinberg SF, Vulliemoz Y. Muscarinic receptor heterogeneity in neonatal rat ventricular myocytes in culture. J Cardiovasc Pharmacol 1996; 27: 455461.

6. Sun LS, Vulliemoz Y, Huber F, Bilezikian JP, Robinson RB. An excitatory muscarinic response in neonatal rat ventricular myocytes and its modulation by sympathetic innervation. $J$ Mol Cell Cardiol 1994; 26: 779-787.

7. Vannucchi MG, Faussone-Pellegrini MS. Differentiation of cholinergic cells in the rat gut during pre- and postnatal life. Neurosci Lett 1996; 206: 105-108.

8. Kolivas S, Volombello T, Shulkes A. Expression of receptors regulating gastric acidity in the developing sheep stomach. Regul Pept 2001; 101: 93-100.

9. Seidel ER, Johnson LR. Ontogeny of gastric mucosal muscarinic receptor and sensitivity to carbachol. Am J Physiol 1984; 246 : G550-G555.

10. Grossman SP. Effects of adrenergic and cholinergic blocking agents on hypothalamic mechanisms. Am J Physiol 1962; 202: 1230-1236.

11. Xu Z, Nijland MJ, Ross MG. Plasma osmolality dipsogenic thresholds and c-fos expression in the near-term ovine fetus. Pediatr Res 2001; 49: 678-685.

12. Xu Z, Glenda C, Day L, Yao J, Ross MG. Central angiotensin induction of fetal brain c-fos expression and swallowing activity. Am J Physiol Regul Integr Comp Physiol 2001; 280: R1837-R1843.

13. Acosta R, Lee JJ, Oyachi N, Buchmiller-Crair TL, Atkinson JB, Ross MG. Anticholinergic suppression of fetal rabbit upper gastrointestinal motility. J Matern Fetal Neonatal Med 2002; 11: 153-157.

14. Tomomasa T, Hyman PE, Hsu CT, Jing J, Snape WJ Jr. Development of the muscarinic receptor in rabbit gastric smooth muscle. Am J Physiol 1988; 254: G680-G686.

15. Oue T, Yoneda A, Shima H, Puri P. Muscarinic acetylcholine receptor expression in aganglionic bowel. Pediatr Surg Int 2000; 16: 267 271.

16. Mitolo-Chieppa D, Schonauer S, Grasso G, Cicinelli E, Carratu MR.
Ontogenesis of autonomic receptors in detrusor muscle and bladder sphincter of human fetus. Urology 1983; 21: 599-603.

17. Lee JG, Macarak E, Coplen D, Wein AJ, Levin RM. Distribution and function of the adrenergic and cholinergic receptors in the fetal calf bladder during mid-gestational age. Neurourol Urodyn 1993; 12 : 599-607.

18. Jimenez Cidre MA. Urinary incontinence: anticholinergic treatment. Rev Med Univ Navarra 2004; 48: 37-42.

19. Brandes SB, Ruggieri MR. Muscarinic receptor subtypes in normal, fetal, and gravid rabbit bladder, heart and uterus. Adv Exp Med Biol 1995; 385: 241-249.

20. Baselli EC, Brandes SB, Luthin GR, Ruggieri MR. The effect of pregnancy and contractile activity on bladder muscarinic receptor subtypes. Neurourol Urodyn 1999; 18: 511-520.

21. Nyirady P, Thiruchelvam N, Godley ML, David A, Cuckow PM, Fry $\mathrm{CH}$. Contractile properties of the developing fetal sheep bladder. Neurourol Urodyn 2005; 24: 276-281.

22. Levin RM, Macarak E, Howard P, Horan P, Kogan BA. The response of fetal sheep bladder tissue to partial outlet obstruction. $J$ Urol 2001; 166: 1156-1160.

23. Kogan BA, Iwamoto HS. Lower urinary tract function in the sheep fetus: studies of autonomic control and pharmacologic responses of the fetal bladder. J Urol 1989; 141: 1019-1024.

24. Paterson D, Nordberg A. Neuronal nicotinic receptors in the human brain. Prog Neurobiol 2000; 61: 75-111.

25. Clementi F. Handbook of experimental pharmacology, neuronal nicotinic receptors. In: Sargent PB (Editor), The distribution of neuronal nicotinic acetylcholine receptors. 2000. $\mathrm{p}$ 163-192.

26. Dani JA. Overview of nicotinic receptors and their roles in the central nervous system. Biol Psychiatry 2001; 49: 166-174.

27. Gotti C, Fornasari D, Clementi F. Human neuronal nicotinic receptors. Prog Neurobiol 1997; 53: 199-237.

28. Hellstrom-Lindahl E, Gorbounova O, Seiger A, Mousavi M, Nordberg A. Regional distribution of nicotinic receptors during prenatal development of human brain and spinal cord. Brain Res Dev Brain Res 1998; 108: 147-160.

29. Falk L, Nordberg A, Seiger A, Kjaeldgaard A, Hellstrom-Lindahl E. The alpha7 nicotinic receptors in human fetal brain and spinal cord. J Neurochem 2002; 80: 457-465.

30. Reddy SC, Panigrahy A, White WF, Kinney HC. Developmental changes in neurotransmitter receptor binding in the human periaqueductal gray. J Neuropathol Exp Neurol 1996; 55: 409-418.

31. Hellstrom-Lindahl E, Seiger A, Kjaeldgaard A, Nordberg A. Nicotineinduced alterations in the expression of nicotinic receptors in primary cultures from human prenatal brain. Neuroscience 2001; 105 : 527-534.

32. Falk L, Nordberg A, Seiger A, Kjaeldgaard A, Hellstrom-Lindahl E. 
Smoking during early pregnancy affects the expression pattern of both nicotinic and muscarinic acetylcholine receptors in human first trimester brainstem and cerebellum. Neuroscience 2005; 132: 389397.

33. Ravikumar BV, Sastry PS. Muscarinic cholinergic receptors in human foetal brain: characterization and ontogeny of $[3 \mathrm{H}]$ quinuclidinyl benzilate binding sites in frontal cortex. J Neurochem 1985; 44: 240246.

34. Ravikumar BV, Sastry PS. Cholinergic muscarinic receptors in human fetal brain: ontogeny of [3H]quinuclidinyl benzilate binding sites in corpus striatum, brainstem, and cerebellum. J Neurochem 1985; 45: 1948-1950.

35. Bar-Peled O, Israeli M, Ben-Hur H, Hoskins I, Groner Y, Biegon A. Developmental pattern of muscarinic receptors in normal and Down's syndrome fetal brain - an autoradiographic study. Neurosci Lett 1991; 133: 154-158.

36. Egozi Y, Sokolovsky M, Schejter E, Blatt I, Zakut H, Matzkel A, et al. Divergent regulation of muscarinic binding sites and acetylcholinesterase in discrete regions of the developing human fetal brain. Cell Mol Neurobiol 1986; 6: 55-70.

37. Schlumpf M, Palacios JM, Cortes R, Lichtensteiger W. Regional development of muscarinic cholinergic binding sites in the prenatal rat brain. Neuroscience 1991; 45: 347-357.

38. Aubert I, Cecyre D, Gauthier S, Quirion R. Comparative ontogenic profile of cholinergic markers, including nicotinic and muscarinic receptors, in the rat brain. J Comp Neurol 1996; 369: 31-55.

39. Berger-Sweeney J. The cholinergic basal forebrain system during development and its influence on cognitive processes: important questions and potential answers. Neurosci Biobehav Rev 2003; 27: 401-411.

40. Lauder JM, Schambra UB. Morphogenetic roles of acetylcholine. Environ Health Perspect 1999; 107 (Suppl 1): 65-69.

41. Adams PR, Brown DA. Synaptic inhibition of the M-current: slow excitatory post-synaptic potential mechanism in bullfrog sympathetic neurones. J Physiol 1982; 332: 263-272.

42. Fibiger HC, Damsma G, Day JC. Behavioral pharmacology and biochemistry of central cholinergic neurotransmission. Adv Exp Med Biol 1991; 295: 399-414.

43. Adams CE, Broide RS, Chen Y, Winzer-Serhan UH, Henderson TA, Leslie FM, et al. Development of the alpha7 nicotinic cholinergic receptor in rat hippocampal formation. Brain Res Dev Brain Res 2002; 139: 175-187.

44. Adams CE. Comparison of alpha7 nicotinic acetylcholine receptor development in the hippocampal formation of $\mathrm{C} 3 \mathrm{H}$ and DBA/2 mice. Brain Res Dev Brain Res 2003; 143: 137-149.

45. Vizi ES, Lendvai B. Modulatory role of presynaptic nicotinic receptors in synaptic and non-synaptic chemical communication in the central nervous system. Brain Res Brain Res Rev 1999; 30: 219235.

46. McGehee DS, Heath MJ, Gelber S, Devay P, Role LW. Nicotine enhancement of fast excitatory synaptic transmission in CNS by presynaptic receptors. Science 1995; 269: 1692-1696.

47. Edwards JA, Cline HT. Light-induced calcium influx into retinal axons is regulated by presynaptic nicotinic acetylcholine receptor activity in vivo. J Neurophysiol 1999; 81: 895-907.

48. Slotkin TA, Cousins MM, Seidler FJ. Administration of nicotine to adolescent rats evokes regionally selective upregulation of CNS alpha 7 nicotinic acetylcholine receptors. Brain Res 2004; 1030: 159-163.

49. Myers CP, Lewcock JW, Hanson MG, Gosgnach S, Aimone JB, Gage $\mathrm{FH}$, et al. Cholinergic input is required during embryonic development to mediate proper assembly of spinal locomotor circuits. Neuron 2005; 46: 37-49.

50. Phelps PE, Barber RP, Brennan LA, Maines VM, Salvaterra PM, Vaughn JE. Embryonic development of four different subsets of cholinergic neurons in rat cervical spinal cord. J Comp Neurol 1990; 291: 9-26.

51. Slotkin TA, Southard MC, Adam SJ, Cousins MM, Seidler FJ. AIpha7 nicotinic acetylcholine receptors targeted by cholinergic developmental neurotoxicants: nicotine and chlorpyrifos. Brain Res Bull 2004; 64: 227-235.

52. Aramakis VB, Metherate R. Nicotine selectively enhances NMDA receptor-mediated synaptic transmission during postnatal development in sensory neocortex. J Neurosci 1998; 18: 8485-8495.

53. Berger-Sweeney J. The effects of neonatal basal forebrain lesions on cognition: towards understanding the developmental role of the cholinergic basal forebrain. Int J Dev Neurosci 1998; 16: 603-612.

54. Ricceri L, Minghetti L, Moles A, Popoli P, Confaloni A, De Simone R, et al. Cognitive and neurological deficits induced by early and prolonged basal forebrain cholinergic hypofunction in rats. Exp Neurol 2004; 189: 162-172.

55. Hohmann CF, Berger-Sweeney J. Cholinergic regulation of cortical development and plasticity. New twists to an old story. Perspect Dev Neurobiol 1998; 5: 401-425.

56. Nijland MJ, Chao CR, Ross MG. Anticholinergic suppression of ovine fetal swallowing activity. Am J Obstet Gynecol 1997; 177: 1105-1112.

57. Joseph SA, Walker DW. Catecholamine neurons in fetal brain: effects on breathing movements and electrocorticogram. J Appl Physiol 1990; 69: 1903-1911.

58. Szeto $\mathrm{HH}$, Hinman DJ. Central muscarinic modulation of fetal blood pressure and heart rate. J Dev Physiol 1990; 13: 17-23.

59. Shi L, Zhang Y, Morrissey $\mathrm{P}, \mathrm{Yao} \mathrm{J}, \mathrm{Xu} Z \mathrm{Z}$. The association of cardiovascular responses with brain c-fos expression after central carbachol in the near-term ovine fetus. Neuropsychopharmacology 2005; 30: 2162-2168.

60. Wei R, Phillips TM, Sternberg EM. Specific up-regulation of $\mathrm{CRH}$ or AVP secretion by acetylcholine or lipopolysaccharide in inflammatory susceptible Lewis rat fetal hypothalamic cells. J Neuroimmunol 2002; 131: 31-40. 